\title{
Reaction-induced surface reconstruction of silver in contact with zirconium
}

\author{
M. Ollivier ${ }^{\mathrm{a}, *}$, R.M. Harker ${ }^{\mathrm{b}}$, C.M. Gourlay ${ }^{\mathrm{a}}$ \\ ${ }^{a}$ Department of Materials, Imperial College London, SW7 2AZ, UK \\ ${ }^{b} A W E$ Aldermaston, Aldermaston, Reading, RG7 $4 P R, U K$
}

\begin{abstract}
When two solid metals are in contact at high temperature, interdiffusion occurs leading in some cases to the growth of intermetallic compounds. The study of nucleation, growth and properties of these intermetallic compounds are of interest since it can be critical for many applications in industries. Yet, the effect of these reactions on the initial surfaces of both metals is not well understood and particularly when surfaces are not perfectly flat and for short contact time. The purpose of the present study is to demonstrate that the growth of an intermetallic compound layer between to solid metals can lead to the surface reconstruction of one of them. The silver-zirconium system will be presented in order to illustrate this new phenomenon. The effect of contact point on the diffusionreaction process has been modelled by patterning the $\mathrm{Zr}$ surface. The nucleation and growth of the intermetallic compounds occur along the contact points which leads to silver surface reconstruction with the growth of the preferential crystal planes $\{111\}$ ad $\{100\}$. A model explaining this new phenomenon is developed based on the minimisation of Gibbs energy and the diffusion rates af both $\mathrm{Ag} \& \mathrm{Zr}$ atoms in the binary system $\mathrm{Ag} / \mathrm{Zr}$.
\end{abstract}

Keywords: Silver, Zirconium, Interdiffusion, Surface, Intermetallic compounds PACS: 81

\section{Introduction}

The solid state diffusion between two metals is a common process used in many industrial situations such as diffusion bonding between two metals of different nature [1, 2]. This process leads sometimes to the formation of intermetallic compound layers (IMCs). The nucleation and growth of these IMCs layers are of interest since these intermetallic compounds provide a good bond between the metals but are generally brittle and may lead to failure in the final product.

Silver is a metal of interest for many industries including dentistry where silver is alloyed with mercury for amalgams $[3,4,5]$, microelectronics for solder purposes [6, 7, 8, 9] and the nuclear industry where silver is used to make control rods in nuclear reactors thanks to the capability of silver to absorb free neutrons $[10,11]$. Moreover, the catalytic properties of silver are widely used by the chemical industry for the epoxidation of ethylene or the partial oxidation of methanol to formaldehyde $[12,13,14]$. Recently, an increased interest has been observed for silver substrates textured for the growth of high temperature superconductors $[15,16,17]$. Finally, the anti-microbial activity of silver has been explored for (bio-) nano-technologies $[18,19,20]$.

In many of these applications, silver is in contact at elevated temperature with another metal and solid state diffusion occurs, involving directly the silver surface and its properties. It is therefore important to study the contact between the silver and a

\footnotetext{
${ }^{*}$ Corresponding author

Email address: o.maelig@imperial.ac.uk (M. Ollivier)
}

metal at elevated temperature. However, when silver is heated under its melting point (e.g. $T<873 \mathrm{~K}$ ), the surface undergoes pronounced morphological changes. These changes are gathered under the term "etching" and have been extensively studied since the early of the $20^{\text {th }}$ century $[21,22,23]$.

The etching of silver includes grain-boundary grooving [24], etch pitting [25, 26] and faceting [27] and can be induced by temperature -thermal etching- and/or by reaction -catalytic etching [28, 29]. The mechanisms of Ag surface reconstruction can be described from a thermodynamic point of view, the driving force being the minimisation of the total Gibbs energy [30]. However, the kinetics of silver atom evaporation has also to be taken into account especially when dealing with heat treatments under vacuum [31, 32]. Multiple parameters can impact the etching of silver. In addition to time and temperature, the presence of oxygen in the atmosphere surrounding the silver surface is known to enhance drastically the faceting and grainboundary grooving $[27,29]$. That is why extensive researches have been done in order to understand the key role of adsorbed oxygen and subsurface oxygen on these morphology changes during catalytic reactions [33, 13, 34, 14, 35].

In order to understand the impact of etching and reaction on the surface of silver at elevated temperature, it has been chosen to study the contact reaction between solid silver and a model metal-here zirconium.

The silver/zirconium system was first described by Karlsson in 1952 [36], with two different non-stoichiometric intermetallic compounds (IMCs) $\mathrm{AgZr}$ and $\mathrm{AgZr}_{3}$. However, the most recent studies based on theoretical [37, 38] and experimental $[39,40]$ investigations contested this early study, and nowa- 
days two stoichiometric IMCs are generally accepted: tetragonal $\mathrm{AgZr}$ and $\mathrm{AgZr}_{2}$, with Strukturbericht Symbol B11 and $\mathrm{C} 11_{b}$, respectively. According to Taguchi \& Iijima [39] in the $\mathrm{Ag} / \mathrm{Zr}$ couple, the diffusion flux of $\mathrm{Ag}$ atoms is larger than that of $\mathrm{Zr}$ atoms, which corroborates the multiple results of selfdiffusion measurements of $\mathrm{Ag}$ tracers in bulk $\mathrm{Zr}$ [41, 42, 43].

One can assume that contact reaction at high temperature between silver and zirconium will then lead to the formation of two IMCs, $\mathrm{AgZr}$ and $\mathrm{AgZr}_{2}$. However, no evidence of silver surface reconstruction has been reported in the literature yet $[39,40]$. This is quite understandable as the study of solid state diffusion between a couple of materials is generally carried out by using (i) laboratory-polished surfaces, (ii) similar sample size, (iii) high applied pressure between the two materials (screw), (iv) long diffusion time and (v) by characterising only the cross-section of the interface.

Nevertheless, in many industrial situations all these conditions are not fulfilled. For example, materials are generally not polished, therefore the surface roughness can be high. Also, in some cases the force applied between two materials can be small and/or non-uniform, compared to a diffusion couple pressed by screws. Finally, edge effects are not taken into account in diffusion couples, although they can be important for industrial geometries.

The purpose of this paper is to demonstrate the impact of the contact reaction between silver and zirconium at elevated temperature and the etching of silver on the morphology of $\mathrm{Ag}$ surface.

\section{Experimental}

The experimental part of this study lies on annealing experiments under vacuum of $\mathrm{Ag} / \mathrm{Zr}$ couples. The effect of contact between $\mathrm{Ag}$ and $\mathrm{Zr}$ has been modelled by using patterned zirconium and polished silver, as described below.

\subsection{Material preparation}

$10 \times 8 \mathrm{~mm}$ coupons of polycrystalline (grain size $20 \mu \mathrm{m}$ ) rolled silver sheets of $0.5 \mathrm{~mm}$ thickness and with a purity of $99.99 \%$ were used for this study. The main impurities of silver sheets are oxygen (20-27 wtppm), lead (14 wtppm) and copper (13 wtppm), and the description of silver sheets processing can be found elsewhere [44]. In order to remove any damage and contamination coming from the rolling process, the surface of the silver coupons was polished as follows: firstly coupons were ground using SiC papers down to "2000 grit" size. Silver samples were then polished using diamond suspensions of $6 \mu \mathrm{m}, 3 \mu \mathrm{m}, 1 \mu \mathrm{m}$ and finally $0.25 \mu \mathrm{m}$. After polishing, silver samples were cleaned using ultrasonic bath of different alcohols in order to remove dusts and organic pollutants.

In order to study the effect of point contact on the $\mathrm{Ag} / \mathrm{Zr}$ diffusion couple, zirconium samples were patterned with an array of $1 \mu \mathrm{m}$-high ridges spaced every $120 \mu \mathrm{m}$. This patterning was performed as follows. A $500 \times 500 \times 1 \mathrm{~mm}$ zirconium sheet supplied by Goodfellow (purity of $99.2 \%$ - main impurities:

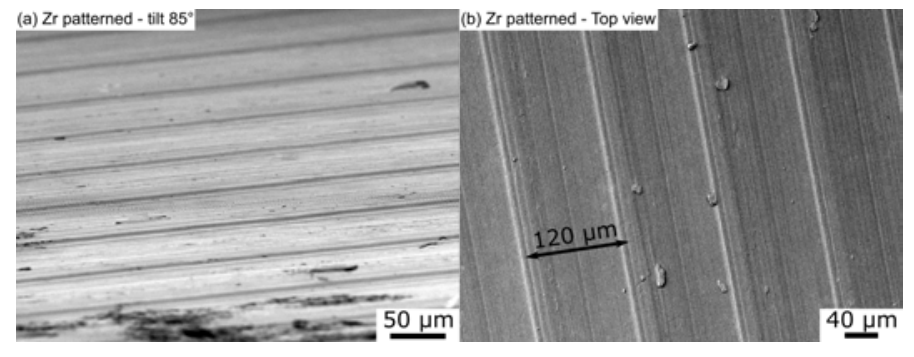

Figure 1: SEM images of the surface of zirconium patterned with an array of $1 \mu \mathrm{m}$-high ridges spaced every $120 \mu \mathrm{m}$. (a) tilt 85 . (b) Top view

hafnium 2500 wtppm and oxygen 1000 wtppm. Grain size 10$20 \mu \mathrm{m})$ was fixed on a rotating stage, while a fine tip was engraving the zirconium surface. The $\mathrm{Zr}$ sheet was then removed and cut into $12 \times 2 \times 1 \mathrm{~mm}$ rods. Dusts and organic pollutants from the machining process were finally removed using a cleaning process consisting of ultrasonic baths with different alcohols. Figure 1 shows SEM images of the patterned $\mathrm{Zr}$ surface where ridges are easily recognisable.

For comparison, some zirconium samples were also polished prior to the $\mathrm{Ag} / \mathrm{Zr}$ couples annealing. The polishing process of zirconium samples was made of a first grinding step using SiC papers down to "4000 grit" size. A second polishing step using a mixture of a suspension of silica particles (OP-S, from Struers) diluted in deionized water and hydrogen peroxide with a volumetric ratio 5:6:1. This polishing step was made on a MD-Chem pad (Struers) and lasted up to 2 hours.

\subsection{Annealing experiments}

Once prepared, the Ag and $\mathrm{Zr}$ samples were set in a stainless steel holder and pressed by screws. Annealing experiments of the $\mathrm{Ag} / \mathrm{Zr}$ couples were performed in a hot-wall alumina tube furnace equipped upstream with a gas panel and downstream with a pumping system. The furnace had a type-K thermocouple directly inserted in the hot zone of the furnace. Before reaching the working pressure of $1 \mathrm{~Pa}$, the furnace was filled with argon $(99.998 \%)$ then purged twice. Heat treatment experiments were then carried out at different temperatures (from 673 to $1073 \mathrm{~K}$ ) and for different dwell times (from $1 \mathrm{~min}$ to 96 hours). The ramp-up was fixed at $20 \mathrm{~K} \cdot \mathrm{min}^{-1}$.

After annealing, the $\mathrm{Ag} / \mathrm{Zr}$ couples were cooled-down slowly. Samples were examined in two configurations. (i) Some samples were studied in cross-section, similar to the standard method used in the study of reactive diffusion, soldering and brazing. This involved mounting in cold resin and polishing with diamond solutions to reveal the Ag-IMC-Zr crosssections. This configuration was particularly adapted for classical polished Ag/polished Zr couples. (ii) For other samples, a technique was developed to detach the $\mathrm{Ag}$ and $\mathrm{Zr}$ sheets after the heat treatment and to study their surfaces directly. This technique was possible here because most of the time, polished Ag $\&$ patterned Zr couples were not or slightly bonded in the experimental conditions studied here (Ag \& patterned $\mathrm{Zr}$ sheets were detached manually, while a screw was used to separate polished Ag \& polished $\mathrm{Zr}$ ). This configuration was found to be useful 
at revealing the contact reaction mechanisms. The different surfaces and interfaces were then characterised by Scanning Electron Microscopy (FEG-SEM, Zeiss Auriga), Energy Dispersive X-ray spectroscopy (EDX, Oxford Instruments) and Electron Back-Scattered Diffraction (EBSD, Quantax Bruker). The subsurface of both silver and zirconium were also investigated by dual column focussed ion beam/SEM microscopy (FIB-SEM, FEI Helios NanoLab 600).

\section{Results \& Discussion}

\subsection{Solid state diffusion between polished Ag E polished $\mathrm{Zr}$}

As it can be seen on Figure 2(a) when polished $\mathrm{Ag}$ and $\mathrm{Zr}$ samples are heat treated at $1073 \mathrm{~K}$ for 720 min under vacuum, reactive interdiffusion occurs, leading to the formation of intermetallic layers composed of $\mathrm{AgZr}$ and $\mathrm{AgZr}_{2}$. The EDX spectrum (Fig. 2(b)) and semi-quantification give values for the $\mathrm{AgZr}$ layer (50.75 at.\% Zr, 49.25 at.\% Ag), and the $\mathrm{AgZr}_{2}$ layer (67.63 at.\% Zr, 32.37 at.\% Ag). The measured thickness of the layers are $\approx 13 \mu \mathrm{m}$ and $\approx 1 \mu \mathrm{m}$, for $\mathrm{AgZr}$ and $\mathrm{AgZr}_{2}$ respectively. These values are slightly smaller than the predicted values obtained from the experimental results of Taguchi \& Iijima [39], but it can be explained by the fact that the time range studied here is outside the time range of Taguchi \& Iijima, therefore the calculated thickness are not accurate. Moreover, for short annealing time, the kinetics of reaction may be different than in the steady state regime.

From the cross-section observation (Fig. 2(a)), no notable surface reconstruction either on $\mathrm{Ag}$ or $\mathrm{Zr}$ side can be seen. When such $\mathrm{Ag} / \mathrm{Zr}$ samples are detached, it is possible to look directly at the surface of both $\mathrm{Ag}$ and $\mathrm{Zr}$. In the middle of the samples, no characteristic reconstruction is observed, except the dimples due to detachment leading to a mechanic deformation of the Ag. Most of the IMC layer is found on the $\mathrm{Zr}$ side (Fig. 2(d)), although on the silver side particles can be seen, suggesting a strong adhesion of the IMCs layer between $\mathrm{Ag}$ and $\mathrm{Zr}$ which is conclusive with the necessity to use tools to detach Ag and Zr (Fig 2(c)).

\subsection{Solid state diffusion between polished Ag $\mathcal{G}$ patterned $\mathrm{Zr}$}

In this section the results of annealing experiments done with polished Ag \& patterned Zr samples will be presented. When necessary, it has been chosen to detach $\mathrm{Ag}$ and $\mathrm{Zr}$ samples in order to characterise the surfaces. SEM mapping of $\mathrm{Ag} \& \mathrm{Zr}$ surfaces has been performed focussing on a zone previously in contact, and using ImageJ to stitch the different images in a larger one. For a better understanding, it has also been chosen to digitally flip Zr SEM images in order to allow a direct comparison between the morphologies observed on both $\mathrm{Ag}$ and $\mathrm{Zr}$ surfaces previously in contact. The authors strongly suggest the reader to print and/or zoom in Figures 3, 4, 5 and 6 while reading the present section.

Figures 3 and 4 show SEM images of $\mathrm{Ag}$ and $\mathrm{Zr}$ surfaces respectively of an Ag-Zr couple annealed at $973 \mathrm{~K}$ for $360 \mathrm{~min}$ under vacuum. The edge of the $\mathrm{Zr}$ rod is visible on the bottom part of the main SEM image on Figure 4. First it is noticeable

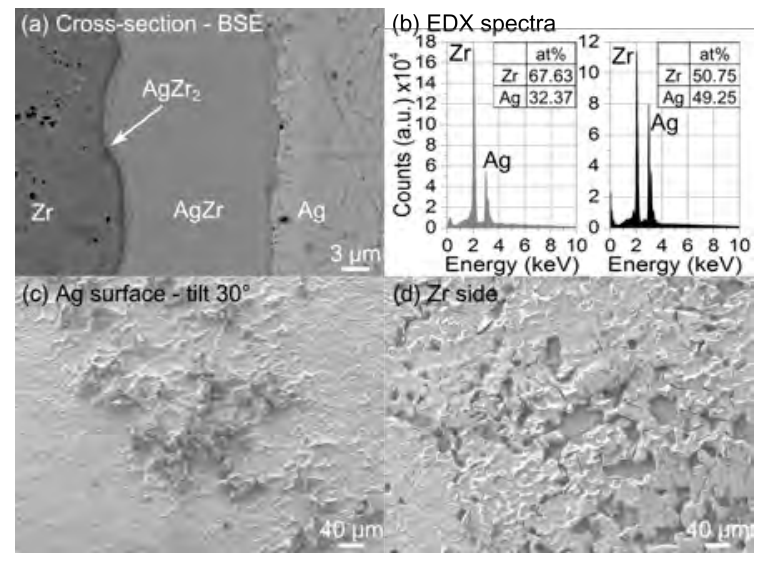

Figure 2: Contact reaction between polished $\mathrm{Ag}$ and polished $\mathrm{Zr}$ for $720 \mathrm{~min}$ at $1073 \mathrm{~K}$, under vacuum $(\mathrm{P}=1 \mathrm{~Pa})$. (a) Back-scattered SEM image of the interdiffusion zone between $\mathrm{Ag}$ and $\mathrm{Zr}$. Two IMCs are visible, $\mathrm{AgZr}$ and $\mathrm{AgZr}_{2}$. (b) EDX spectra of the $\mathrm{AgZr}_{2}$ (grey) and $\mathrm{AgZr}$ (black) IMCs layer. (c) SEM image of the surface of Ag after being detached: IMCs particles can be observed. (d) SEM image of the $\mathrm{Zr}$ side, where a thick IMCs is visible. Holes due to IMCs stitched on the Ag surface are visible.

that both surfaces have been impacted by annealing. On the Ag side, the initial polished surface is greatly modified in the vicinity of the $\mathrm{Zr}$ contact, while an IMC layer has grown on the $\mathrm{Zr}$ side (note that IMC has not been found on the Ag surface). However all the surfaces are not impacted in the same way. The top of the SEM images show non-impacted Ag \& Zr surfaces, which can be explained by an asymmetric contact between both metals, with a strong contact on the edge (see bottom of $\mathrm{Ag}$ side) and almost no contact on top of the image: the array of ridges is still visible on the $\mathrm{Zr}$ side and the smooth/flat surface of $\mathrm{Ag}$ (with annealing twins) can be seen in the top-left corner.

The main observation is that the contact points (i.e. Zr ridges) are the place where the IMC layer grows, which in turn modifies the Ag surface. Moreover, since different regions are at different stages of contact reaction and some surface regions are unreacted, this experiment reveals important details of the IMC nucleation and growth mechanisms in the early stages of a contact reaction. By comparing regions at different stages of the contact reaction, the sequence of events and reaction mechanisms can be inferred.

Three zones have been highlighted and magnified on Figures 3 and 4, each of them corresponding to a particular stage of IMC layer growth.

The first zone (a) displays a detail related to IMC nucleation on both surfaces. On the $\mathrm{Zr}$ side (Fig. 4a) one can see a circular protuberance. In mirror, a circular depression is observable on the Ag side (Fig. 3a). This particular morphology is interpreted as an IMCs in the early stage of nucleation localised at a contact point between $\mathrm{Ag}$ and $\mathrm{Zr}$. This morphology will be extensively characterised in section 3.3.

In the second zone (b), it is possible to see on the $\mathrm{Zr}$ side (see Fig. 4b) multiple protuberances which have coalesced because of lateral growth. This growth is accompanied on the Ag surface by the formation of trenches and faceted pits due to surface diffusion of $\mathrm{Ag}$ atoms towards the intermetallic com- 
pounds. The topography of the Ag surface does not match with the topography observed on the $\mathrm{Zr}$ surface. Moreover, these surface modifications occur not only under the IMC but also in the vicinity of the protuberance growth, suggesting a high mobility of $\mathrm{Ag}$ atomes on the surface. It is noteworthy that the faceted pits are comparable to the ones observed on a free Ag surface submitted to a thermal treatment under vacuum [45, 46, 44].

The last highlighted zone (c) is characterised by an IMC layer on the $\mathrm{Zr}$ side while the $\mathrm{Ag}$ surface is smoother (see Figs. 3c and $4 \mathrm{c}$ ). The IMC layer growth may be controlled by a vertical growth, the lateral expansion being localised next to the contact points (see top-right corner of Figure 4). In mirror to the IMC layer, the surface morphology of silver may be explained by a smoothing effect on previously pitted surface: on the first steps of IMC nucleation and lateral growth, Ag atoms coming from the local Ag surface diffuse towards nucleation site, forming pits and facets in order to minimise the total Gibbs energy. While the IMC layer growth continues the faceted pits are covered with IMC thus the Ag surface is smoothed.

With the purpose of enhancing the surface modifications of silver surface in contact with patterned zirconium the temperature and time of $\mathrm{Ag}-\mathrm{Zr}$ contact annealing was increased during another experiment to $1073 \mathrm{~K}$ and $720 \mathrm{~min}$, respectively. The results of this experiment are presented on Figures 5 and 6 for Ag surface and $\mathrm{Zr}$ surface, respectively. For a better understanding, the SEM images of patterned $\mathrm{Zr}$ surface have been digitally flipped.

First, it is clear that both $\mathrm{Ag}$ and $\mathrm{Zr}$ surfaces have been deeply impacted by the diffusion annealing. On the Ag side, the surface is clearly modified and IMCs has grown on the $\mathrm{Zr}$ side. Also, the heterogeneity of surface morphologies observed can be explained by an asymmetric contact between $\mathrm{Ag}$ and $\mathrm{Zr}$, with a stronger contact on the bottom-right corner than on the topleft corner. This hypothesis suggests it is possible to have a chronological approach within a single experiment. Four zones have been highlighted on the main SEM images, each will be discussed in turn.

On zone (a) it is possible to observe the early stage of nucleation of a protuberance on the $\mathrm{Zr}$ surface, with in mirror a small depression on the Ag side (see Fig. 5a and 6a).

Figure $6 \mathrm{~b}$ shows a morphology not present at lower annealing temperature and time on $\mathrm{Zr}$ surface. This morphology develops between ridges and can be described as impinged particles. The growth of these particles may be explained by two factors: no contact between $\mathrm{Ag}$ and $\mathrm{Zr}$ between two ridges and a higher temperature leading to a high evaporation rate of Ag atoms, going to react with $\mathrm{Zr}$ on the opposite side. This hypothesis is also supported by the faceted pits found in mirror on the $\mathrm{Ag}$ side (see Fig. 5b), which can correspond to the morphology of the Ag surface after an evaporation process occurred.

Also, along the Ag-Zr contact zone (ridges) surface modifications became more complex as it can be seen on Figures $5 \mathrm{c}$ and $6 \mathrm{c}$. On these ridges the IMC layer which grew on the $\mathrm{Zr}$ surface is thick and flat compared to the evaporation zones (between ridges), while the surface of $\mathrm{Ag}$ appears to be highly faceted with the presence of holes (see top-left corner of Fig. $5 c)$. These holes are also faceted and may be interpreted as ab- normal pitting. It can be assumed that the surface contact area between $\mathrm{Ag}$ and $\mathrm{Zr}$ in these zones consists only of edges-toedges point contact since the morphologies of both $\mathrm{Ag}$ and $\mathrm{Zr}$ surfaces are not identical. The Ag faceting may be due to the minimization of the total Gibbs energy which is coupled with the diffusion-reaction of $\mathrm{Ag}$ atoms when the IMC grows.

In the bottom-left corner of Figure 6 both IMCs grown on the $\mathrm{Zr}$ surface, respectively between and at the ridges, merged and a uniform layer will grow (see Fig. 6d). On the other hand, the Ag surface is highly faceted showing little contact with the $\mathrm{Zr}$ surface (see Fig. 5d). For stronger contact (not shown here) the facets are less pronounced, and one can assume that the Ag surface has been smoothed by the growth of the IMC layer perpendicular to the $\mathrm{Ag}-\mathrm{Zr}$ sheets.

\subsection{Characterisation of protuberances}

A SEM image at higher magnification of a typical protuberance is shown on Figure 7a. Its surface is rough and rings can be seen on the edges. These rings may be due to either growth steps or mechanical strain. Some silver particles also exist on top of this protuberance, as it can be seen from the side (see Fig. 7b). In order to have access to the whole protuberance morphology, a FIB sputter etching was carried out and cross-section SEM images recorded (see Fig. 7c). It is noteworthy that a thin layer is observable at the bottom of the protuberance (see arrow on Fig. 7c), suggesting the growth of two intermetallic compounds. With the purpose of correctly identify the composition of the main IMC of the protuberance, a FIB sputter etching was done parallel to the $\mathrm{Zr}$ surface and an EDX spectrum has been acquired (see Fig. 7d). The EDX semi-quantification gives 49,2 at\% $\mathrm{Ag}$ and 50.8 at\% $\mathrm{Zr}$, which is consitatn with $\mathrm{AgZr}$.

The identification of the second IMC layer was possible by combining FIB-SEM sample preparation and EBSD. First a foil of the protuberance was lifted out using a FIB-SEM microscope and placed on a home-made specimen holder (see Fig. 8a). Then the protuberance cross-section surface was cleaned with FIB milling, whereby the current and the voltage of the ion beam was tuned from high values to low values at the end of the cleaning. The prepared specimen was then transferred to the SEM-EBSD microscope and an EBSD map was acquired. As it can be seen on the phase map in Figure 8c two phases are identified, corresponding to the two intermetallic compounds known in the literature: the main part of the protuberance is made of $\mathrm{AgZr}$, while a thin layer of $\mathrm{AgZr}_{2}$ is at the bottom (see Fig. $8 \mathrm{~b}$ for the crystalline structure of these two compounds). The inverse pole figure along the $\mathrm{x}$ axis displayed on Figure 8 reveals that both $\mathrm{AgZr}$ and $\mathrm{AgZr}{ }_{2}$ are polycrystalline.

Based on Figures 7 and 8 as well as on the fact that Ag atoms diffuse faster than $\mathrm{Zr}$ atoms in $\mathrm{Ag}-\mathrm{Zr}$ system [39], it can be inferred that most of IMCs growth takes place in the $\mathrm{Zr}$ sheets. This point explains why IMC layer is only found on the $\mathrm{Zr}$ side when Ag-Zr sheets are detached.

\subsection{Ag faceting - EBSD characterisation}

To understand the facets observed locally on the silver surface after annealing in contact with $\mathrm{Zr}$ (e.g. in Figure 5d) the 

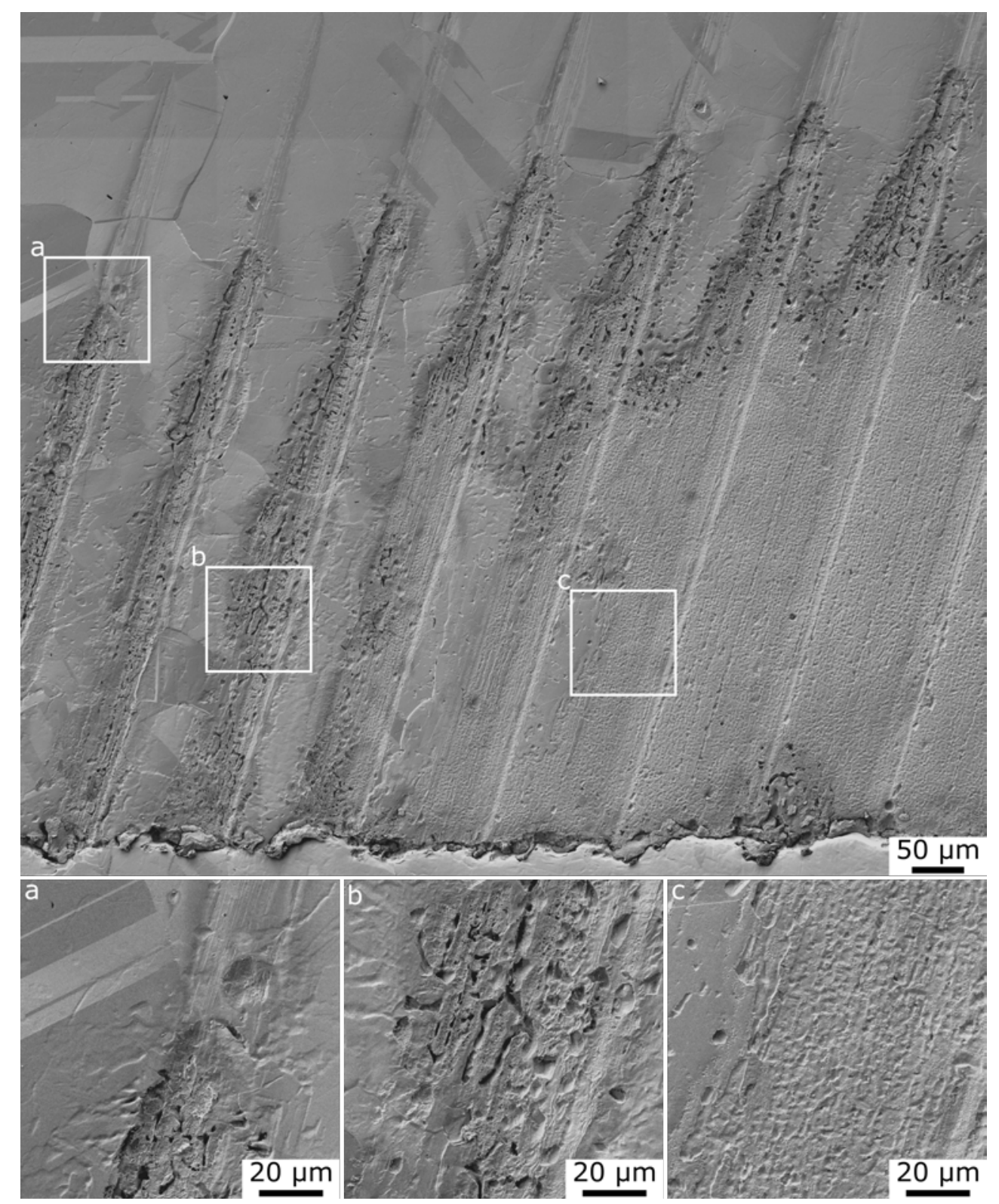

Figure 3: Polished Ag surface after annealing in contact with patterned $\mathrm{Zr}$ at $973 \mathrm{~K}$ for 360 min under vacuum $(\mathrm{P}=1 \mathrm{~Pa})$.

crystal planes of these facets were studied by EBSD. Figure 9a shows a SEM image of a faceted Ag zone where an EBSD acquisition has been done (dotted rectangle). Despite the non-flat surface, a large fraction of the Kikuchi patterns have been resolved as it can be seen from the inverse pole figure along the $\mathrm{x}$ axis presented in Figure 9b, the main dark regions being facets not scanned by the electron beam because of the 70 angle between the sample surface and the beam in the configuration of the EBSD detection. In the same way it has been possible to identify different grains (see Fig. 9c), each corresponding to a particular appearance of the facets. Thus, the crystal orientation of each grain can be determined and the crystal planes on the surface indirectly identified. Figure 9d displays the crystal orientation of $\mathrm{Ag}$ for the identified grains, where it can be inferred that the facets are the $\{111\}$ and $\{100\}$ family of planes.
Thus, similar to past studies on the thermal etching of Ag, the Ag faceting is consistent with the surface reconstruction to minimise the total Gibbs energy.

\subsection{Model of surface reconstruction}

To the best of our knowledge, the reconstruction of a surface during a solid state reaction diffusion process has not been described in the literature yet. This may be explained by the particular system described here: $(i) \mathrm{Ag}$ is known to etch thermally but $\mathrm{Zr}$ is not; (ii) $\mathrm{Ag}$ atom diffusion is faster than $\mathrm{Zr}$ atoms diffusion in the $\mathrm{Ag} / \mathrm{Zr}$ couple; (iii) this study involved intermittent contact and regions without contact due to the use of the patterned $\mathrm{Zr}$ and $\mathrm{Ag}$ sheets, which is relevant to $\mathrm{Ag}$ in various industrial uses.

Based on the experiments and characterisation, a model of the surface modification for both $\mathrm{Ag}$ and $\mathrm{Zr}$ can be suggested. 


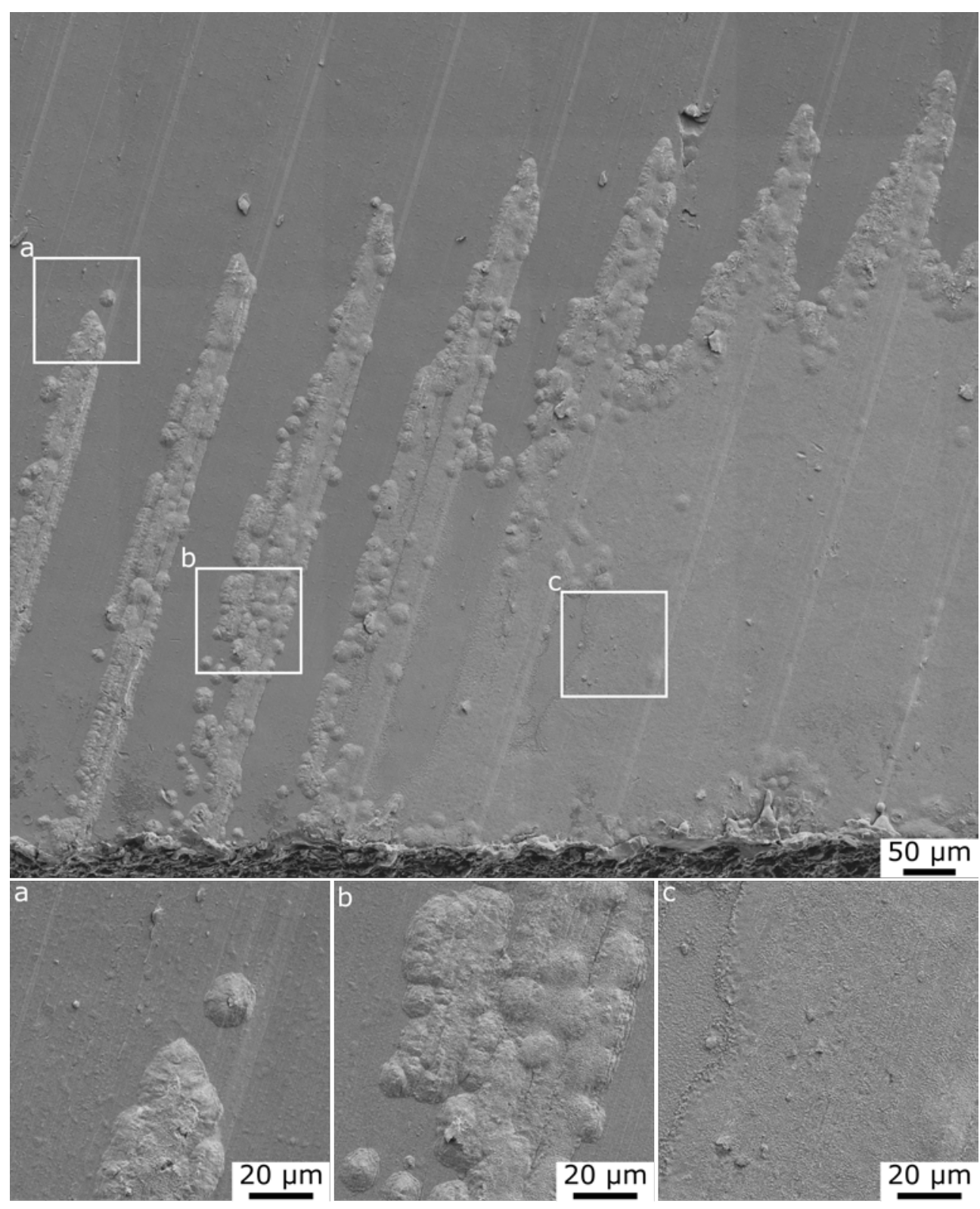

Figure 4: Flipped SEM images of patterned Zr surface after annealing in contact with polished Ag at $973 \mathrm{~K}$ for 360 min under vacuum $(\mathrm{P}=1 \mathrm{~Pa})$.

Initially the Ag-Zr couple is in contact only along the ridges on the patterned $\mathrm{Zr}$ and can be modelled in two dimensions as on Figure 10a, where the surface of $\mathrm{Ag}$ is flat (bottom) and the surface of $\mathrm{Zr}$ is patterned with triangular ridges (top).

When this system is held at high temperature, first the native oxide of silver $\mathrm{Ag}_{2} \mathrm{O}$ decomposes into $\mathrm{Ag}$ and $\mathrm{O}_{2}$ above $725 \mathrm{~K}[47,48]$ and the native zirconium oxide $\mathrm{ZrO}_{2}$ dissolves into the $\mathrm{Zr}$ as the solubility for $\mathrm{O}$ is relatively high at $T<970 \mathrm{~K}$ [49, 50]. Ag and $\mathrm{Zr}$ then react at the contact points, which occurs by the nucleation of intermetallic compounds in accordance with the Ag-Zr binary diagram. This nucleation is possible via the diffusion of $\mathrm{Ag}$ and $\mathrm{Zr}$ atoms as sketched on Figure $10 \mathrm{~b}$. $\mathrm{Ag}$ and $\mathrm{Zr}$ atoms move towards the $\mathrm{Ag}-\mathrm{Zr}$ contact either by (1) surface diffusion, or (2) volume diffusion. The nucleated IMC then grows laterally in the form of a protuberance (see Figs. 4a and 7).

In parallel, if the annealing temperature is sufficiently high (e.g. $1073 \mathrm{~K}$ ) atom sublimation may occur away from the Ag$\mathrm{Zr}$ contact, which leads to the nucleation of intermetallic compounds particles between ridges (see (3) on Fig. 10b). The melting point of $\mathrm{Ag}$ being lower that of $\mathrm{Zr}$, it can be assumed that the Ag sublimation rate is higher than that of $\mathrm{Zr}$, thus the growth of IMC particles will take place on the $\mathrm{Zr}$ surface. This point is supported by the SEM observations (see Fig. 6).

With time, the nucleated IMCs protuberances and particles grow. This growth is accompanied by a surface reconstruction of silver which is driven by the minimisation of free energy, and leads to the preferential formation of high-density family planes in FCC crystals, i.e. $\{111\}$ and $\{100\}$ planes (see Fig 10c). Such reconstruction is common for silver surfaces alone and can take 


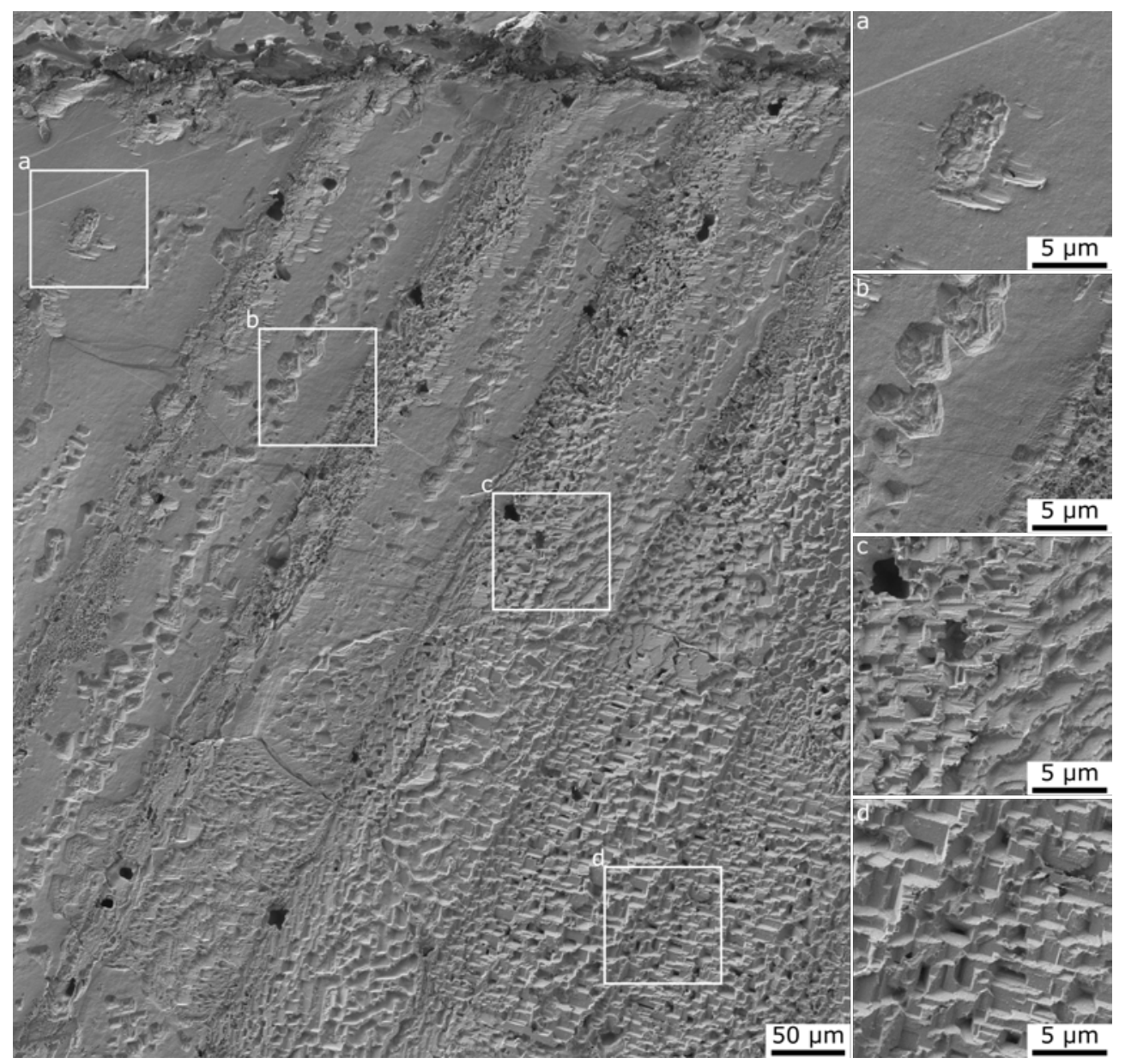

Figure 5: Polished Ag surface after annealing in contact with patterned $\mathrm{Zr}$ at $1073 \mathrm{~K}$ for 720 min under vacuum $(\mathrm{P}=1 \mathrm{~Pa})$.

different forms, for example faceting or etch pitting [32, 51]. This phenomenon combines multiple mechanisms such as a high mobility of $\mathrm{Ag}$ atoms on the surface and $\mathrm{Ag}$ sublimation at high temperature. In the case of $\mathrm{Ag}-\mathrm{Zr}$ contact reactions the $\mathrm{Ag}$ atoms are more mobile than $\mathrm{Zr}$ atoms, which explains the high reconstruction of the Ag surface observed on Figure 5 and $9 \mathrm{a}$ for example. The higher Ag diffusion can be deduced from the relative position of $\mathrm{AgZr}$ and $\mathrm{AgZr}_{2}$ (see Figs. 2 and 8) as well as from the IMCs growth shifted in $\mathrm{Zr}$ (no IMCs found on Ag side, see Figs. 3 and 5).

Finally, the lateral growth of IMCs will eventually lead to the merging of discrete protuberances, so a full layer of intermetallic compounds will be formed. The reconstructed Ag surface is therefore covered by an intermetallic compounds layer, limiting the evaporation process as well as the diffusion length of $\mathrm{Ag}$ atoms before reaction with $\mathrm{Zr}$, which in turn leads to the smoothing of Ag surface (see Fig. 10d). This possible mechanism is based in particular on the smooth surface of Ag observed where the $\mathrm{Ag}-\mathrm{Zr}$ contact is strong (see for example $3 \mathrm{c}$ ). 


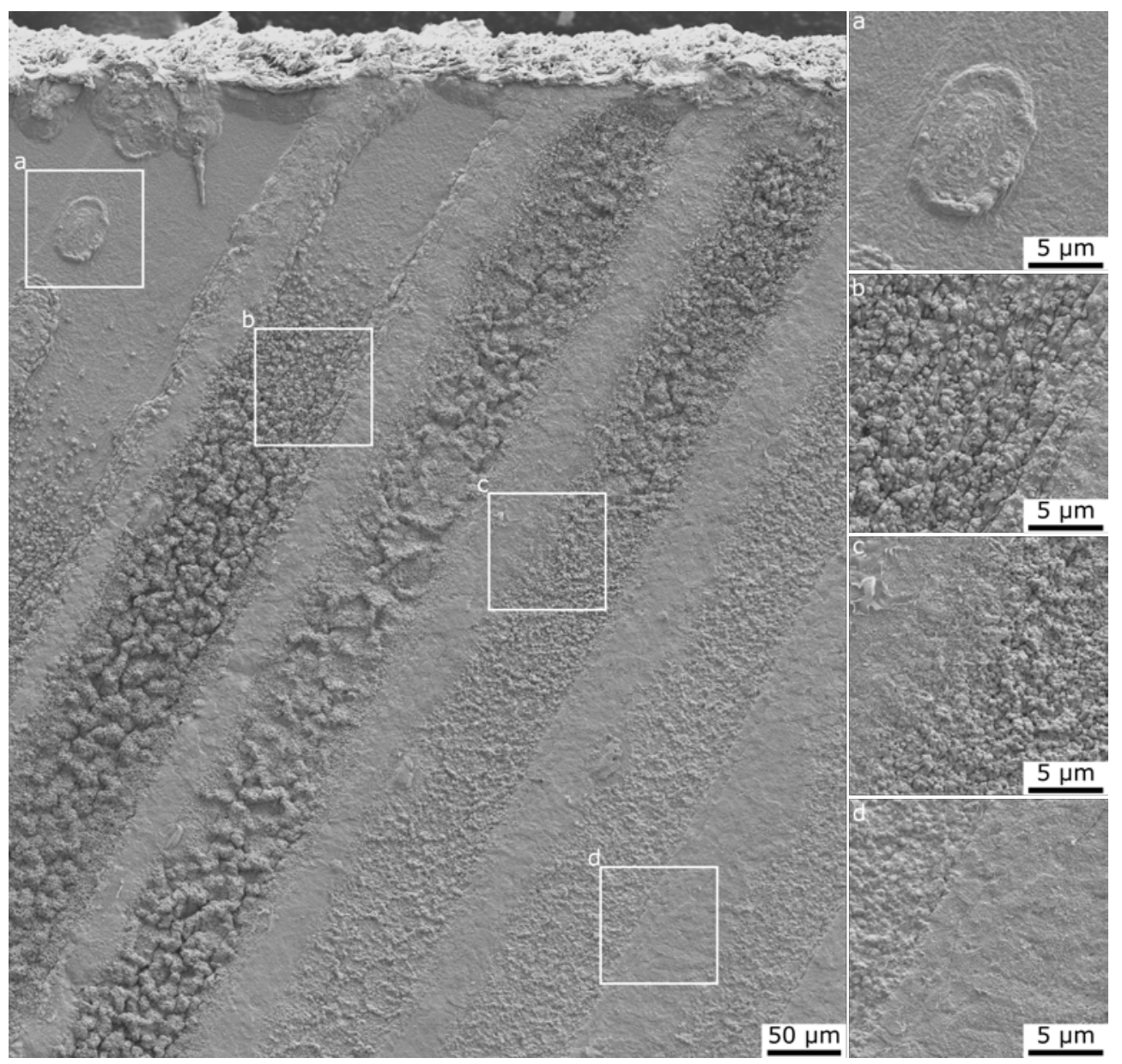

Figure 6: Flipped SEM images of patterned Zr surface after annealing in contact with polished Ag at $1073 \mathrm{~K}$ for 720 min under vacuum $(\mathrm{P}=1 \mathrm{~Pa})$.

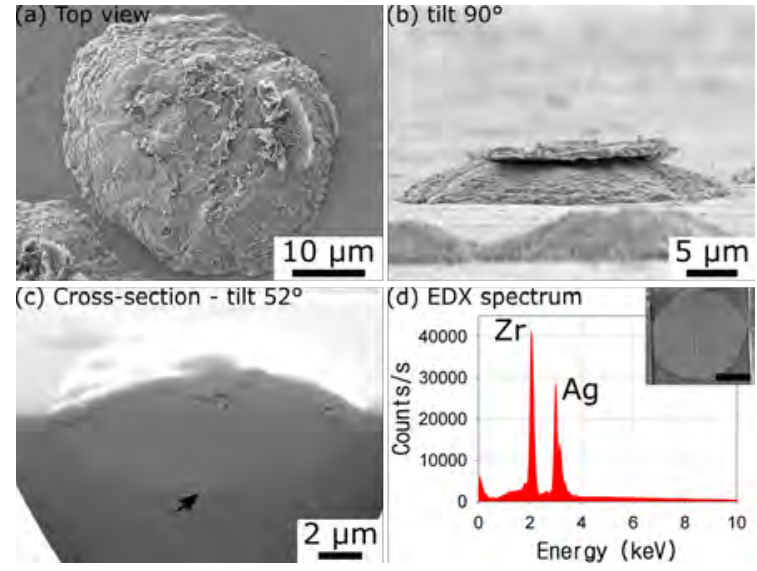

Figure 7: SEM characterisation of a typical protuberance. (a) top view. (b) Side view $(\approx 90)$. (c) Cross-section SEM image of a protuberance after FIB sputter etching (tilt 52, Pt deposit); the arrow indicates a second layer on the bottom. (d) EDX spectrum recorded after FIB sputter etching of a protuberance (see inset, scale bar $=5 \mu \mathrm{m})$. AgZr is identified.

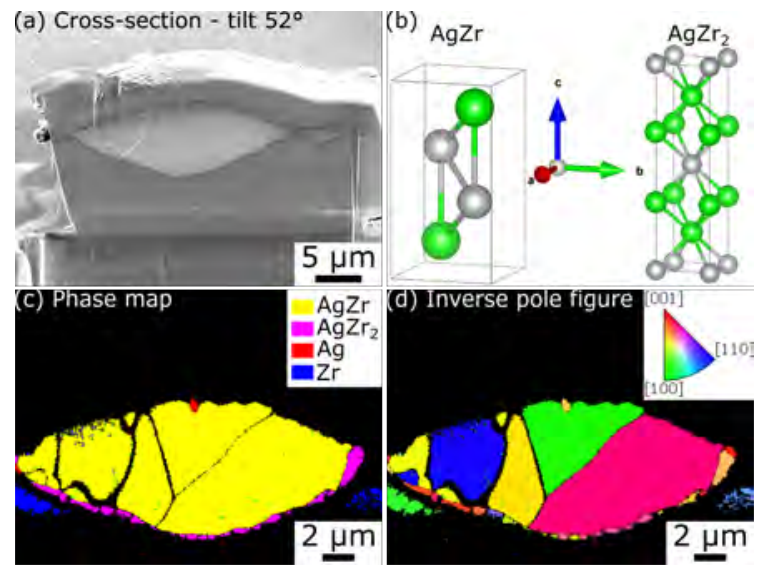

Figure 8: EBSD characterisation of a typical protuberance. (a) Foil of a protuberance prepared by FIB-SEM. (b) Crystalline structure of $\mathrm{AgZr}$ and $\mathrm{AgZr}_{2}$ compounds identified in the literature; $\mathrm{Ag}$ atoms are in grey and $\mathrm{Zr}$ atoms in green. (c) Map of the phases identified by EBSD. (d) Inverse pole figure map along the $\mathrm{x}$ axis of the protuberance. In inset the unit triangle denotes the crystallographic orientations of the tetragonal stucture common for both phases. 


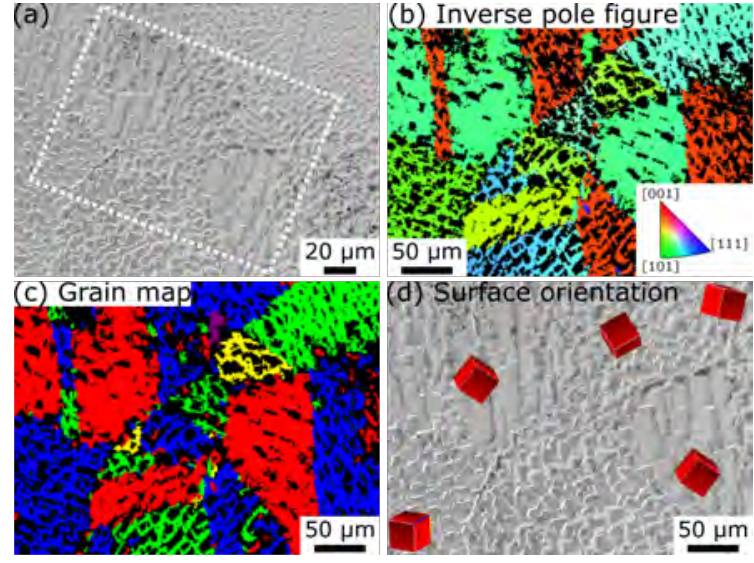

Figure 9: EBSD characterisation of faceted Ag surface. (a) SEM image of the scanned zone. (b) Inverse pole figure along the $\mathrm{x}$ axis of the Ag surface. (c) Grains map. (d) Crystal orientation of Ag grains.

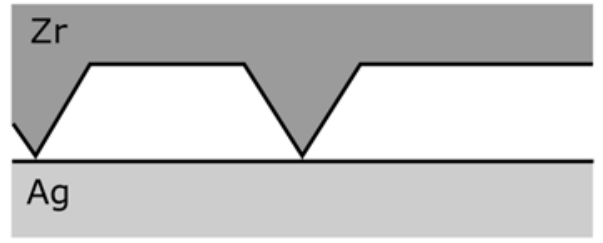

(a) Initial state

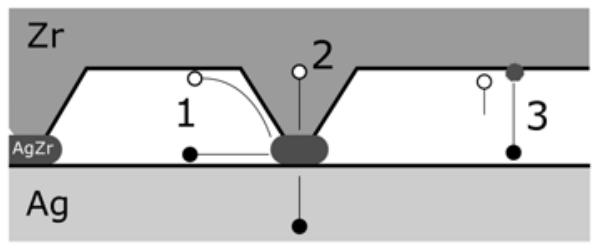

(b) Nucleation of IMC protuberance

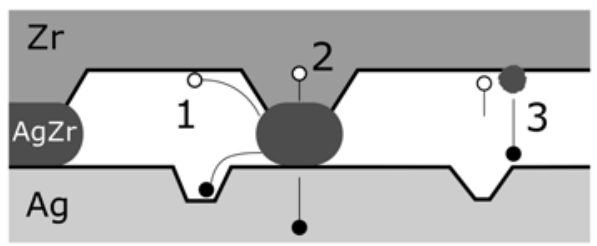

(c) Growth

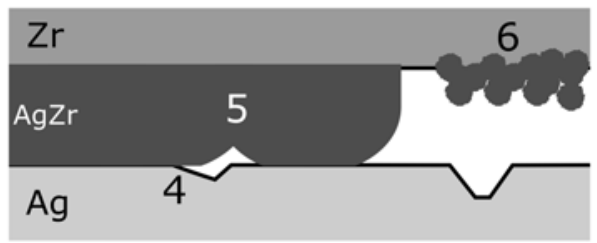

(d) Impingement of IMCs

Figure 10: Model of surface modification for Ag-Zr couple.

\section{Conclusion}

The effect of contact reaction and thermal etching on the surface modifications of silver has been studied by annealing polished $\mathrm{Ag}$ and patterned $\mathrm{Zr}$ couples. Once $\mathrm{Ag} \& \mathrm{Zr}$ are detached, intermetallic compounds are observed on the $\mathrm{Zr}$ side while the Ag surface displays a large rage of morphologies such as etch pits, faceting or holes. The intermetallic compounds have been identified as stoichiometric (poly-)crystalline $\mathrm{AgZr}$ and $\mathrm{AgZr}_{2}$. A particular morphology called protuberance has been characterised as early stage growth site of IMCs on a contact point, the lateral growth and merging of these protuberances leading to an IMCs layer with time. At high temperature the nucleation and growth of IMCs is also possible via vapour transport of $\mathrm{Ag}$ atoms reaching the $\mathrm{Zr}$ surface in places far from the contact points. The mechanisms responsible of Ag surface modifications are driven by the minimisation of the total Gibbs energy and lead to the formation of facets oriented along the high-density crystal planes, $\{111\}$ and $\{100\}$. The contribution of surface diffusion and free evaporation of $\mathrm{Ag}$ atoms to the $\mathrm{Ag}$ surface modifications have been identified during the nucleation and coalescence steps. The merging of local IMCs growth leads to the formation of a uniform layer, which in turn will smooth the Ag surface since the diffusion path for Ag atoms to react with $\mathrm{Zr}$ is smaller.

\section{Acknowledgements}

(C) British Crown Owned Copyright 2016/AWE. Published with permission of the Controller of Her Britannic Majesty's Stationery Office.

\section{References}

[1] G. He, H. Liu, Q. Tan, J. Ni, Diffusion bonding of Ti2.5A12.5Mo2.5Zr and CoCrMo alloys, Journal of Alloys and Compounds 509 (27) (2011) $7324-7329$.

[2] Y. Wang, G. Luo, J. Zhang, Q. Shen, L. Zhang, Microstructure and mechanical properties of diffusion-bonded $\mathrm{Mg}-\mathrm{Al}$ joints using silver film as interlayer, Materials Science and Engineering: A 559 (2013) 868-874.

[3] S. Dunne, I. Gainsford, N. Wilson, Current materials and techniques for direct restorations in posterior teeth: Part 1: silver amalgam, International Dental Journal 47 (3) (1997) 123-136. doi:10.1002/j.1875595X.1997.tb00777.x.

[4] B. Darvell, Development of strength in dental silver amalgam, Dental materials 28 (10) (2012) E207-E217. doi:10.1016/j.dental.2012.05.002.

[5] B. Darvell, Effect of corrosion on the strength of dental silver amalgam, Dental materials 28 (9) (2012) E160-E167. doi:10.1016/j.dental.2012.06.001.

[6] Z. Zhang, W. Zhu, Controllable synthesis and sintering of silver nanoparticles for inkjet-printed flexible electronics, Journal of Alloys and Compounds 649 (2015) 687-693.

[7] X. Milhet, P. Gadaud, V. Caccuri, D. Bertheau, D. Mellier, M. Gerland, Influence of the porous microstructure on the elastic properties of sintered Ag paste as replacement material for die attachment, Journal of Electronic Materials 44 (10) (2015) 3948-3956.

[8] S. Belyakov, C. Gourlay, Metastable eutectic in Pb-free joints between Sn-3.5Ag and Ni-based substrates, Materials letters 148 (2015) 91-95. doi:10.1016/j.matlet.2015.02.073.

[9] A. Pearl, M. Osterman, M. Pecht, Evaluation of ENEPIG and immersion silver surface finishes under drop loading, Journal of Electronic Materials 45 (1) (2015) 391-402. 
[10] L. Sepold, T. Lind, A. P. Csordas, U. Stegmaier, M. Steinbruck, J. Stuckert, AgInCd control rod failure in the QUENCH-13 bundle test, Annals of Nuclear Energy 36 (9) (2009) 1349-1359. doi:http://dx.doi.org/10.1016/j.anucene.2009.06.020.

[11] R. Dubourg, H. Austregesilo, C. Bals, M. Barrachin, J. Birchley, T. Haste, J. Lamy, T. Lind, B. Maliverney, C. Marchetto, A. Pinter, M. Steinbruck, J. Stuckert, K. Trambauer, A. Vimi, Understanding the behaviour of absorber elements in silver-indium-cadmium control rods during $\{\mathrm{PWR}\}$ severe accident sequences, Progress in Nuclear Energy 52 (1) (2010) 97108. doi:http://dx.doi.org/10.1016/j.pnucene.2009.09.012.

[12] L. Lefferts, J. van Ommen, J. Ross, The oxidative dehydrogenation of methanol to formaldehyde over silver catalysts in relation to the oxygensilver interaction, Applied Catalysis 23 (2) (1986) 385-402.

[13] A. Nagy, G. Mestl, D. Herein, G. Weinberg, E. Kitzelmann, R. Schlogl, The correlation of subsurface oxygen diffusion with variations of silver morphology in the silver-oxygen system, Journal of Catalysis 182 (2) (1999) 417-429.

[14] G. Waterhouse, G. Bowmaker, J. Metson, Mechanism and active sites for the partial oxidation of methanol to formaldehyde over an electrolytic silver catalyst, Applied Catalysis A: General 265 (1) (2004) 85-101.

[15] T. Doi, Y. Hakuraku, N. Kashima, S. Nagaya, Biaxially oriented $\mathrm{NdBa}_{2} \mathrm{Cu}_{3} \mathrm{O}_{7}$ films prepared on $\{100\}<001>$ textured Ag tapes without any buffer layers, Physica C: Superconductivity 372-376, Part 2 (2002) 775-778. doi:doi:10.1016/S0921-4534(02)00904-8.

[16] Z. Zhang, K. Sekine, Development of single sharp $\{011\}<211>$ recrystallization texture in polycrystalline silver by severe plastic deformation at room temperature, Materials Science \& Engineering, A: Structural Materials: Properties, Microstructure and Processing 423 (1-2, SI) (2006) 243-246. doi:10.1016/j.msea.2005.12.035.

[17] S. Kim, H. Han, H. Jeong, D. Lee, Evolution of $\{110\}<110>$ texture in silver sheets, Materials Research Innovations 15 (1) (2011) S390-S394. doi:10.1179/143307511X12858957675110.

[18] C. Li, N. Lu, Q. Xu, J. Mei, W. Dong, J. Fu, Z. Cao, Decahedral and icosahedral twin crystals of silver: Formation and morphology evolution, Journal of Crystal Growth 319 (1) (2011) 88-95. doi:http://dx.doi.org/10.1016/j.jcrysgro.2011.01.068.

[19] X. Xia, J. Zeng, Q. Zhang, C. Moran, Y. Xia, Recent developments in shape-controlled synthesis of silver nanocrystals, The Journal of Physical Chemistry C 116 (41) (2012) 21647-21656. doi:10.1021/jp306063p.

[20] Y. Wang, D. Wan, S. Xie, X. Xia, C. Huang, Y. Xia, Synthesis of silver octahedra with controlled sizes and optical properties via seedmediated growth, ACS Nano 7 (5) (2013) 4586-4594, pMID: 23631674. doi: $10.1021 / \mathrm{nn} 401363 \mathrm{e}$

[21] R. Shuttleworth, R. King, B. Chalmers, Thermal etching of silver, Nature 158 (1946) 482-483.

[22] B. Chalmers, R. King, R. Shuttleworth, The thermal etching of silver, Proceedings of the Royal Society of London. Series A, Mathematical and Physical Sciences 193 (1035) (1948) 465-483.

[23] A. Moore, The influence of surface energy on thermal etching, Acta Metallurgica 6 (4) (1958) 293-304.

[24] W. Mullins, Theory of thermal grooving, Journal of Applied Physics 28 (3) (1957) 333-339.

[25] A. Hendrickson, E. Machlin, A thermal etching technique for revealing dislocations in silver, Acta Metallurgica 3 (1) (1955) 64-69.

[26] J. Hirth, L. Vassamillet, Correlation of thermal etch pits with dislocations in silver, Journal of Applied Physics 29 (3) (1958) 595-595.

[27] G. Rhead, H. Mykura, Thermal etching of silver in various atmospheres, Acta Metallurgica 10 (9) (1962) 843-856.

[28] M. Flytzani-Stephanopoulos, L. Schmidt, Morphology and etching processes on macroscopic metal catalysts, Progress in Surface Science 9 (3) (1979) 83-111.

[29] T. Wei, J. Phillips, Thermal and catalytic etching: Mechanisms of metal catalyst reconstruction, Advances in Catalysis 41 (1996) 359-421.

[30] C. Herring, Some theorems on the free energies of crystal surfaces, Physical Review 82 (1951) 87-93.

[31] W. Winterbottom, J. Hirth, Vaporization kinetics of solid silver, New York, London; printed in Northern Ireland, 1964

[32] X. Bao, G. Lehmpfuhl, G. Weinberg, R. Schlogl, G. Ertl, Variation of the morphology of silver surfaces by thermal and catalytic etching, Journal of the Chemical Society-Faraday Transactions 88 (6) (1992) 865-872.

[33] G. Millar, J. Metson, G. Bowmaker, R. Cooney, In-situ Raman studies of the selective oxidation of methanol to formaldehyde and ethene to ethylene-oxide on a polycrystalline silver catalyst, Journal of the Chemical Society-Faraday Transactions 91 (22) (1995) 4149-4159.

[34] A. Nagy, G. Mestl, R. Schlgl, The role of subsurface oxygen in the silvercatalyzed, oxidative coupling of methane, Journal of Catalysis 188 (1) (1999) 58-68.

[35] T. Rocha, A. Oestereich, D. Demidov, M. Havecker, S. Zafeiratos, G. Weinberg, V. Bukhtiyarov, A. Knop-Gericke, R. Schlogl, The silveroxygen system in catalysis: new insights by near ambient pressure $\mathrm{X}$ ray photoelectron spectroscopy, Physical Chemistry Chemical Physics 14 (2012) 4554-4564.

[36] N. Karlsson, An X-ray study of the phases in the silver-zirconium system, Acta Chemica Scandinavica 6 (1952) 1424-1430.

[37] I. Karakaya, W. Thompson, The Ag-Zr (silver-zirconium) system, Journal of Phase Equilibria 13 (2) (1992) 143-146.

[38] D. H. Kang, I.-H. Jung, Critical thermodynamic evaluation and optimization of the $\mathrm{Ag}-\mathrm{Zr}, \mathrm{Cu}-\mathrm{Zr}$ and $\mathrm{Ag}-\mathrm{Cu}-\mathrm{Zr}$ systems and its applications to amorphous Cu-Zr-Ag alloys, Intermetallics 18 (5) (2010) 815-833.

[39] O. Taguchi, Y. Iijima, Reaction-diffusion in silver-zirconium system, Materials Transactions JIM 35 (10) (1994) 673-678.

[40] X. He, Y. Wang, H. Liu, Z. Jin, Investigation of the isothermal section of the $\mathrm{Ag}-\mathrm{Zr}-\mathrm{Y}$ ternary system at $1023 \mathrm{~K}$ by diffusion-triple, Journal of Alloys and Compounds 417 (1) (2006) L1-L3.

[41] R. Tendler, C. Varotto, Silver diffusion in zirconium, Journal of Nuclear Materials 54 (2) (1974) 212-216.

[42] K. Vieregge, C. Herzig, Tracer diffusion of silver in alpha-zirconium single- and polycrystals, Journal of Nuclear Materials 165 (1) (1989) 6573.

[43] Y. Iijima, O. Taguchi, Diffusion of copper and silver in zirconium, Journal of Materials Science Letters 14 (7) (1995) 486-489.

[44] M. Ollivier, R. Harker, C. Gourlay, Etch pitting and subsurface pore growth during the thermal etching of silver, Philosophical Magazine Letters 95 (11) (2015) 547-554. doi:10.1080/09500839.2015.1121298.

[45] H. Patel, Thermal etch pattern on silver crystals, Current Science 34 (24).

[46] K. Kawabuchi, T. Suzuki, Variations in orientation of etch pits on (100) and (111) surfaces of silver, Journal of Crystal Growth 8 (3) (1971) 288290.

[47] G. Waterhouse, G. Bowmaker, J. Metson, The thermal decomposition of silver (I, III) oxide: a combined XRD, FT-IR and Raman spectroscopic study, Physical Chemistry Chemical Physics 3 (17) (2001) 3838-3845.

[48] A. De Rooij, Corrosion in space.

[49] V. Konev, A. Nadolskii, L. Minyacheva, Mechanism of oxygen dissolution in metallic zirconium, Oxidation of Metals 47 (3-4) (1997) 237-245.

[50] M. Reif, F. Scherm, M. C. Galetz, U. Glatzel, An enhanced three-step oxidation process to improve oxide adhesion on zirconium alloys, Oxidation of Metals 82 (1-2) (2014) 99-112.

[51] W. Meulenberg, O. Teller, U. Flesch, H. Buchkremer, D. Stver, Improved contacting by the use of silver in solid oxide fuel cells up to an operating temperature of 800C, Journal of Materials Science 36 (13) (2001) 31893195 . 